\title{
Research Article \\ Seismic Performance of Steel Frames with Semirigid Connections
}

\author{
Iman Faridmehr, ${ }^{1}$ Mahmood Md. Tahir, ${ }^{1}$ Tom Lahmer, ${ }^{2}$ and Mohd Hanim Osman ${ }^{3}$ \\ ${ }^{1}$ UTM Construction Research Centre (CRC), Institute of Smart Infrastructures and Innovative Construction, \\ Universiti Teknologi Malaysia (UTM), 81300 Skudai, Johor, Malaysia \\ ${ }^{2}$ Institute of Structural Mechanics-Structural Analysis and Component Strength, Bauhaus University, Weimar, Germany \\ ${ }^{3}$ Forensic Engineering Centre (FEC), Universiti Teknologi Malaysia (UTM), 81300 Skudai, Johor, Malaysia \\ Correspondence should be addressed to Mahmood Md. Tahir; mahmoodtahir@utm.my
}

Received 2 August 2016; Revised 12 November 2016; Accepted 9 January 2017; Published 30 April 2017

Academic Editor: Kyoung Kwan Ahn

Copyright (c) 2017 Iman Faridmehr et al. This is an open access article distributed under the Creative Commons Attribution License, which permits unrestricted use, distribution, and reproduction in any medium, provided the original work is properly cited.

\begin{abstract}
The nonlinear stiffness matrix method was incorporated to investigate the structural performance of steel portal frames with semirigid connections. A portal frame with unstiffened extended end-plate connection was designed to demonstrate the adequacy of the proposed method. Besides, the seismic performance of steel portal frames with semirigid connections was investigated through time history analysis where kinematic hysteresis model was assigned to semirigid connections to account for energy dissipation and unloading stiffness. Based on the results of the study, it was found that generally semirigid connections influenced the force distribution which resulted in the decrease in base shear and lighter frame compared to the rigid one. The results also indicated that there was no direct relationship between maximum displacement at the top and connection stiffness in high-rise frames.
\end{abstract}

\section{Introduction}

The structural behaviour of steel portal frame is mainly associated based on its connection's performance. Accordingly, the accurate modelling of steel portal frame needs to take into account realistic connection modelling if an accurate response is desired to be achieved. It is a usual engineering practice to consider either perfect simple or fully rigid connections between beam and column. Experimental tests, however, have acknowledged the real behaviour of beam-tocolumn connections in someplace between these two unrealistic models that possess remarkable flexibility. Based on the majority of design regulations it is only necessary to consider the connection flexibility for the third category; however, it is predicted that majority of beam to column connection types have semirigid performance in some fashion.

The rigidity of beam-to-column connections have relationship with geometrical factors of the connection components, that is, angle section, bolts size, and end-plate. Widespread research projects that consist of numerical and experimental tests have been done so far to demonstrate moment-rotation relationship which is suitable to estimate the ideal behaviour of semirigid connections [1-6]. Based on the results of the above studies which differ from linear model to power and polynomial models, a large and growing number of literatures has investigated the seismic performance of steel portal frames with semirigid connections [7-11]. The findings of these studies suggested that adequately designed semirigid beam-to-column connections and frames should be associated with ductile and steady hysteretic performance. The results also revealed that there was a direct relationship between connection stiffness and base shear; however, the lateral drift did not decrease linearly by increasing the connection stiffness. It was also highlighted that ideal structure should incorporate the least probable base shear reaction with satisfactory lateral sway. Many researchers have investigated analytically the seismic behaviour of semirigid frames [1215]. The results give evidence that there was a substantial potential to use semirigid structures whose seismic behaviour is similar to that of rigid one mainly in moderate seismic areas. Moreover, the semirigid frames possess benefit of longer first mode period and therefore attract smaller inertial loads. This issue compensates the effect of the enlarged flexibility. 


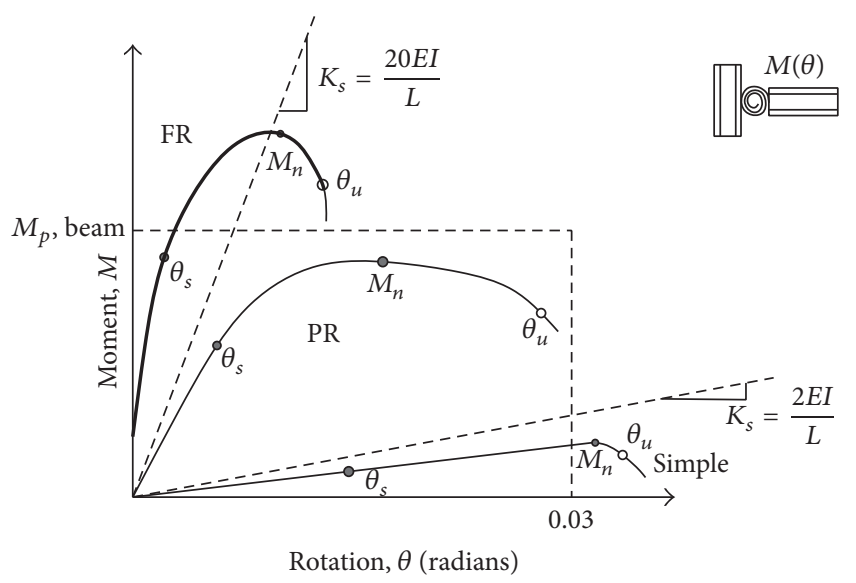

Figure 1: Moment-rotation curves for connections [16].

It appears from the aforementioned investigations that numerous researches have studied the effects of frames with semirigid connections. However, far too little attention has been paid to the hysteresis modelling of semirigid connections to account for decreasing energy dissipation and unloading stiffness with increasing plastic deformation. The present study explores the influence of semirigid connection on structural performance of steel portal frame through analytical study. The seismic performance of steel portal frames also was investigated through nonlinear time history analysis where kinematic hysteresis model was assigned to semirigid connections to consider energy dissipation capacity and stiffness degradation. The required parameters for the above-mentioned hysteresis models were extracted from eight full-scale experimental tests results of unstiffened extended end-plate connections conducted at Universiti Teknologi Malaysia.

\section{AISC and Eurocode Classification of Beam-to-Column Connections}

According to the AISC, the beam-to-column connection is classified based on the characteristics of moment-rotation $(M-\theta)$ curve. It covers strength, stiffness, and ductility of the beam-to-column connections. The secant stiffness, $K_{s}$, at service loads is a fundamental criterion of the connection stiffness as defined in

$$
K_{s}=\frac{M_{s}}{\theta_{s}},
$$

where $M_{s}$ is moment at service load, $(\mathrm{kN}-\mathrm{m})$ and $\theta_{s}$ is rotation at service load, rad.

If $k_{s} L / E I \geq 20$, the connection is considered to be fully rigid or FR connections (able to preserve the rotation between members). If $k_{s} L / E I \leq 2$, the connection is classified as simple (it rotates without increasing moment). The connection stiffness between these two boundaries is categorized as a partially restrained "PR" or semirigid connection (see Figure 1), and the strength, ductility, and stiffness of the beam-to-column connections should be taken into account in the analysis process.
The maximum moment can be carried out by connection introduced as $M_{n}$, as shown in Figure 1. Connections with a lesser amount of $20 \%$ of the plastic moment of the connected beam, $M_{p}$, at a the rotation of $0.02 \mathrm{rad}$, are supposed to have no flexural capacity for analysis. It is worth mentioning that, for FR connection, strength less than the beam strength is anticipated. Yet, it is also probable for a PR connection to provide a moment capacity higher than the connected beam [6].

In Eurocode 3 Part 1-8 [17] the classification of beam-tocolumn joint may be classified as rigid, nominally pinned, or semirigid by comparing its initial rotational stiffness, $S_{j \text {.ini }}$, with connected beam stiffness. The connections that are categorized as fully rigid are supposed to have an adequate rotational stiffness to consider analyses based on fully rigid. The following equation represents rigid connection boundaries:

$$
S_{j . \mathrm{ini}} \geq \frac{K_{b} E I_{b}}{L_{b}},
$$

where $K_{b}$ is taken as 8 for fully rigid structures, $K_{b}$ is taken as 25 for other frames, $I_{b}$ is moment inertia of connected beam, and $L_{b}$ is the length of connected beam.

A supposedly simple connection should be capable of transferring the external forces, without increasing substantial moments that influence adversely members or the structure as a whole. According to Eurocode 3 Part 1-8, the connections are considered as nominally pinned if

$$
S_{j . \text { ini }} \leq \frac{0.5 E I_{b}}{L_{b}} .
$$

The beam-to-column connections that do not address the criteria for FR connections or a simple connections shall be classified as partially restrained (PR) or semirigid connections. PR connections provide an anticipated deformation between connected members, based on the $(M-\theta)$ curve features of the connections. PR connections are supposed to convey the shear forces as well as bending moments. The initial stiffness, $S_{j . \text { ini }}$, of beam-to-column connections is determined through flexibility of its main elements; each element is characterized by an elastic stiffness coefficient, $k_{i}$. The initial rotational stiffness, $S_{j \text {.ini }}$, of a beam-to-column connection calculated with an accuracy from following equation is recommended by Eurocode 3 Part 1-8 [17]:

$$
S_{j}=\frac{E z^{2}}{\mu \sum_{i}\left(1 / k_{i}\right)},
$$

where $k_{i}$ is the stiffness coefficient for basic joint component $i, z$ is the lever arm of extended end-plate connection, and $\mu$ is the stiffness ratio $\left(S_{j . \text { ini }} / S_{j}\right)$.

\section{Performance of Portal Frames with Semirigid Connections Using Analytical Method}

Analysis of semirigid frames requires accurately predicting the connection's performance. Nonlinear behaviour of connections through moment-rotation curve and some of the 


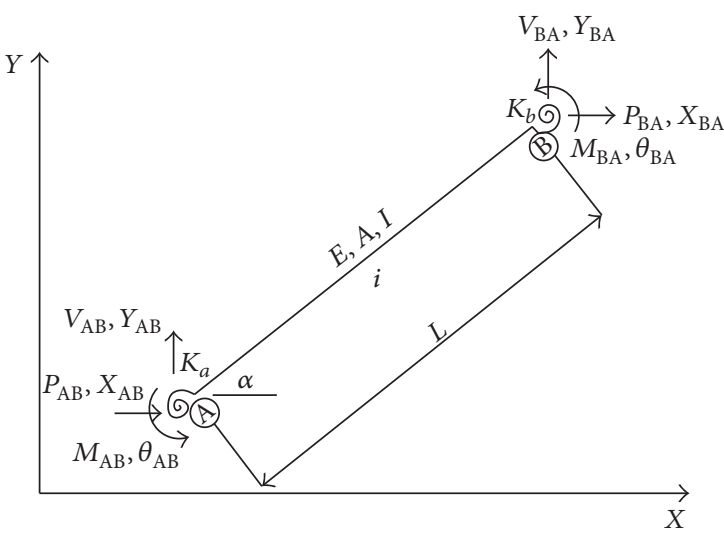

(a)

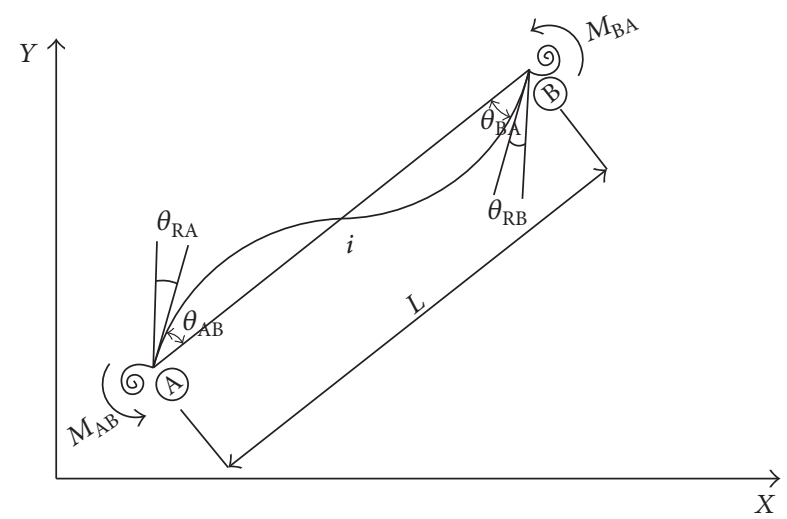

(b)

FIgURE 2: (a) Forces and displacements and (b) rotations in the semirigid frame component.

analytical method are used to predict them. This analytical method is defined as the moment-rotation relationship achieved by a decent curve to full-scale experimental test results. One of the most famous methods which is used in this study is suggested by Frye and Morris. This method is characterized through an odd power polynomial as

$$
\theta_{r}=c_{1}(K M)^{1}+c_{2}(K M)^{3}+c_{3}(K M)^{5},
$$

where $\theta_{r}$ is the rotation of connection, $M$ is the applied moment to connection, $K$ is the normalized parameter relation between connection category and geometry, and $c_{1}, c_{2}$, and $c_{3}$ are defined as the moment-rotation curve parameters.

Chen and Lui [18] provide the value of these parameters for different type of connections. The flexibility of connection is obtained as follows:

$$
S=\frac{d M}{d \theta}=\frac{1}{c_{1} K+3 c_{2}(K M)^{2}+5 c_{3}(K M)^{4}} .
$$

The initial stiffness was to be considered whenever the connection is unloaded and calculated as.

$$
S=\frac{d M}{d \theta}=\frac{1}{c_{1} K} .
$$

The main drawback of this formulation is that the tangent connection stiffness may become negative at some value of connection moment $M$. This is physically unacceptable, and the negative stiffness may cause numerical difficulties in the analysis of frame structures if the tangent stiffness formulation is used. Following the procedure of Frye-Morris (1975), Picard et al. (1976) and Altman et al. (1982) developed prediction equations to describe the $M-\theta r$ curve for strapangle connections and top- and seat-angle connection with double web angles, respectively. Goverdhan (1983) reestimated the size parameters in the standardization constant $K$ for flush end-plate connections to get a good agreement with moment-rotation curves obtained from experimental results.

3.1. Nonlinear Stiffness Matrix of Beam with Semirigid Connections. During the analysis of steel portal frame with semirigid beam-to-column connections, the influence of connection flexibility is considered through assigning rotational joint possessing stiffness $K_{a}$ and $K_{b}$ to both ends of component as shown in Figure 2.

The nonlinear stiffness matrix of component $i$ with considering internal axial force and semirigidity connections at both ends in global system has the following form:

$$
[S]=\left|\begin{array}{cccccc}
a & & & & & \\
b & d & & & S Y M \\
c_{1} & e_{1} & f_{1} & & & \\
-a & -b & -c_{1} & a & & \\
-b & -d & -e_{1} & b & d & \\
-c_{2} & -e_{2} & f_{2} & c_{2} & e_{2} & g
\end{array}\right|,
$$

where

$$
\begin{aligned}
& a=\frac{E A}{L} \times \cos ^{2} \alpha+\frac{12 E I}{L^{3}} \times f_{x 1} \times \emptyset_{5} \times \sin ^{2} \alpha \\
& b=\left(\frac{E A}{L}-\frac{12 E I}{L^{3}} \times f_{x 1} \times \emptyset_{5}\right) \cos \alpha \sin \alpha \\
& d=\frac{E A}{L} \times \sin ^{2} \alpha+\frac{12 E I}{L^{3}} \times f_{x 1} \times \emptyset_{5} \times \cos ^{2} \alpha \\
& c_{1}=-\frac{6 E I}{L^{2}} \times f_{x 2} \times \emptyset_{2} \times \sin \alpha \\
& c_{2}=-\frac{6 E I}{L^{2}} \times f_{x 3} \times \emptyset_{2} \times \sin \alpha \\
& f_{1}=\frac{4 E I}{L} \times f_{x 4} \times \emptyset_{3} \\
& f_{2}=\frac{2 E I}{L} \times f_{x 5} \times \emptyset_{3} \\
& e_{1}=-\frac{6 E I}{L^{2}} \times f_{x 2} \times \emptyset_{2} \times \cos \alpha \\
& e_{2}=-\frac{6 E I}{L^{2}} \times f_{x 3} \times \emptyset_{2} \times \cos \alpha \\
& g=\frac{4 E I}{L} \times f_{x 6} \times \emptyset_{4},
\end{aligned}
$$


where $E$ is module of elasticity, $L, I, A$, and $\alpha$ are the length, moment of inertia, area, and cosine direction of the element, respectively. The influence of the connection flexibility is considered in the matrix by adapting the stiffness expressions of fully rigid component through the following equations [19]:

$$
\begin{aligned}
& f_{x 1}=\frac{\left(K_{a} \times K_{b}+K_{a}+K_{b}\right)}{K K} \\
& f_{x 2}=\frac{K_{a}\left(K_{b}+2\right)}{K K} \\
& f_{x 3}=\frac{K_{b}\left(K_{a}+2\right)}{K K} \\
& f_{x 4}=\frac{K_{a}\left(K_{b}+3\right)}{K K} \\
& f_{x 5}=k_{a} \times \frac{K_{b}}{K K} \\
& f_{x 6}=\frac{K_{b}\left(K_{a}+3\right)}{K K} \\
& K K=K_{a} K_{b}+4\left(K_{a}+K_{b}\right)+12,
\end{aligned}
$$

where $K_{a}$ and $K_{b}$ are the stiffness of flexible connections at two ends of the component. This rotational stiffness is calculated as tangent stiffness through nonlinear parameter given in (5). The influences of axial forces are incorporated in the nonlinear matrix through considering functions of $\emptyset_{1}, \emptyset_{2}$, $\emptyset_{3}, \emptyset_{4}$, and $\emptyset_{5}$ as follows [20]:

$$
\begin{aligned}
& \emptyset_{1}=\beta \cot \beta \\
& \emptyset_{2}=\frac{\beta^{2}}{\left(3-3 \emptyset_{1}\right)} \\
& \emptyset_{3}=\frac{3 \emptyset_{2}+\emptyset_{1}}{4} \\
& \emptyset_{4}=\frac{3 \emptyset_{2}-\emptyset_{1}}{2} \\
& \emptyset_{5}=\emptyset_{1} \emptyset_{2},
\end{aligned}
$$

where

$$
\begin{aligned}
& \beta=0.5 \pi \sqrt{\rho} \\
& \rho=\frac{F_{1}}{P_{\text {cr }}}=\frac{F_{1} l^{2}}{\left(\pi^{2} E I\right)} .
\end{aligned}
$$

In the above equations $F_{1}$ is the axial force in the component and $P_{\mathrm{cr}}$ is the Euler critical load of hinge-ended element with identical geometry and stiffness of the component. By calculating stiffness matrix for each individual components, the global stiffness matrix which incorporated the effects of large deformations and flexibility of connections can be calculated. This process is nonlinear and requires iterative analysis. Accordingly, applied loads are divided into some

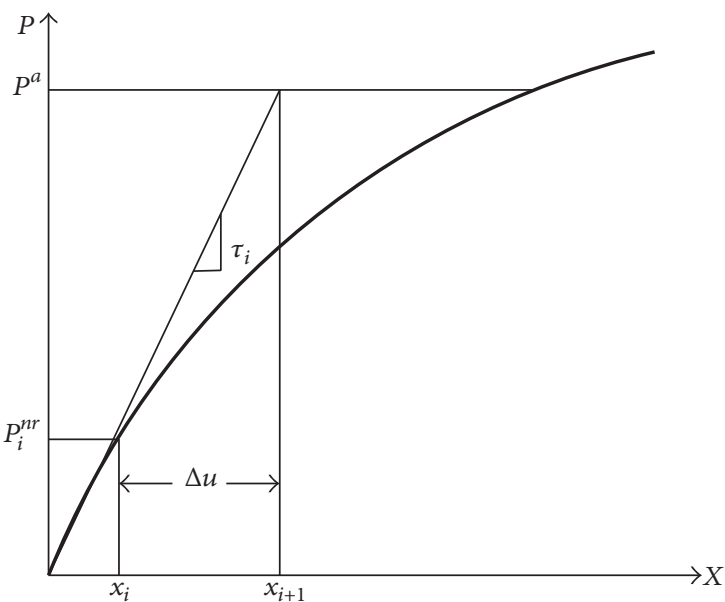

FIGURE 3: Newton-Raphson solution, one iteration.

smaller parts and stiffness matrix equations are considered as incremental load as follows:

$$
\{\Delta P\}=[\tau]\{\Delta X\},
$$

where $[\tau]=\sum_{i=1}^{m}[S]_{i}$ is the stiffness matrix of whole structure, $\{\Delta P\}$ is the incremental force vector, and $\{\Delta X\}$ is the incremental displacement vector.

By using (13) the quantity of $\{\Delta X\}$ in each stage can be calculated. However, as long as the component and connection stiffness are considered constant during the analysis, the structure equilibrium equations cannot be satisfied. To address this problem, Newtown-Raphson force vector are applied to (13) in each stage. The Newton-Raphson method is an iterative process of solving the nonlinear equations and can be written as

$$
\begin{aligned}
{\left[\tau_{i}^{T}\right]\left\{\Delta x_{i}\right\} } & =\left\{P^{a}\right\}-\left\{P_{i}^{n r}\right\} \\
\left\{x_{i+1}\right\} & =\left\{x_{i}\right\}+\left\{\Delta x_{i}\right\},
\end{aligned}
$$

where $\left[\tau_{i}^{T}\right]$ is Jacobian matrix, $i$ is subscript representing the current equilibrium iteration, and $\left\{P_{i}^{n r}\right\}$ is vector of restoring loads corresponding to the element internal loads.

As can be seen in Figure 3, more than one NewtonRaphson iteration is needed to obtain a converged solution. The general algorithm proceeds as follows:

1. Assume $\left\{x_{0}\right\} .\left\{x_{0}\right\}$ is usually the converged solution from the previous time step. On the first time step, $\left\{x_{0}\right\}=\{0\}$.

2. Compute the updated tangent matrix $\left[\tau_{i}^{T}\right]$ and the restoring load $\left\{P_{i}^{n r}\right\}$ from configuration $\left\{x_{i}\right\}$.

3. Calculate $\left\{\Delta x_{i}\right\}$ from (14).

4. Add $\left\{\Delta x_{i}\right\}$ to $\left\{x_{i}\right\}$ in order to obtain the next approximation $\left\{x_{i+1}\right\}(15)$.

5. Repeat steps (2) to (4) until convergence is obtained. 


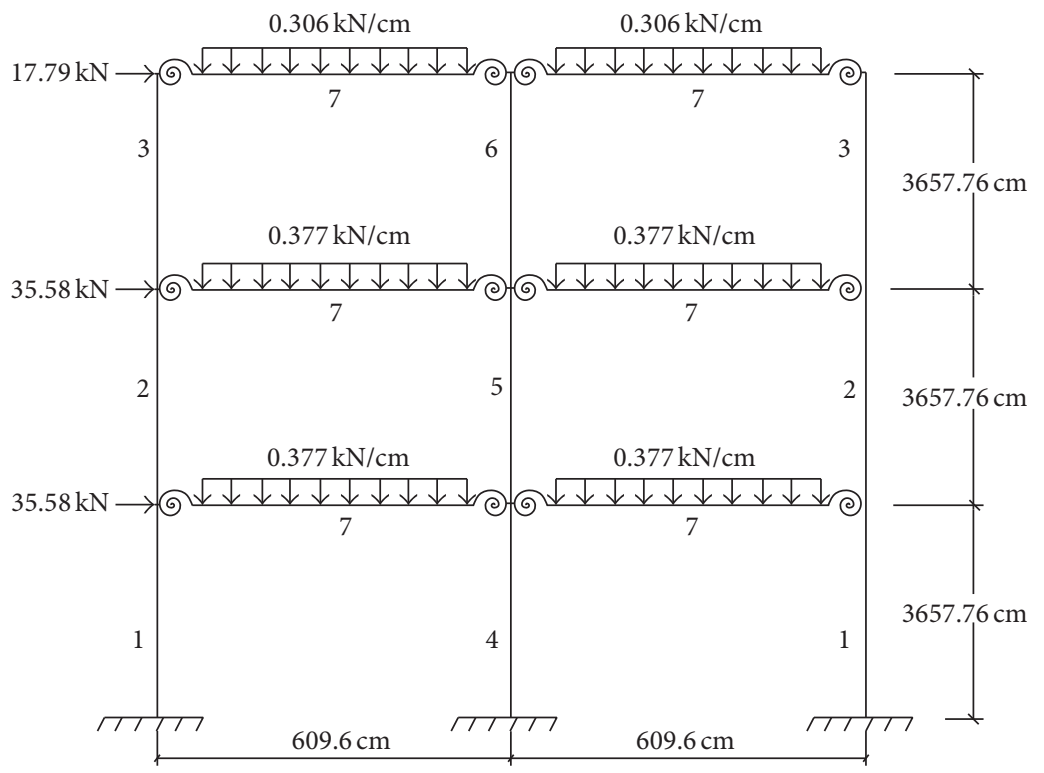

FIGURE 4: Unbraced steel portal frame with semirigid connections [21].
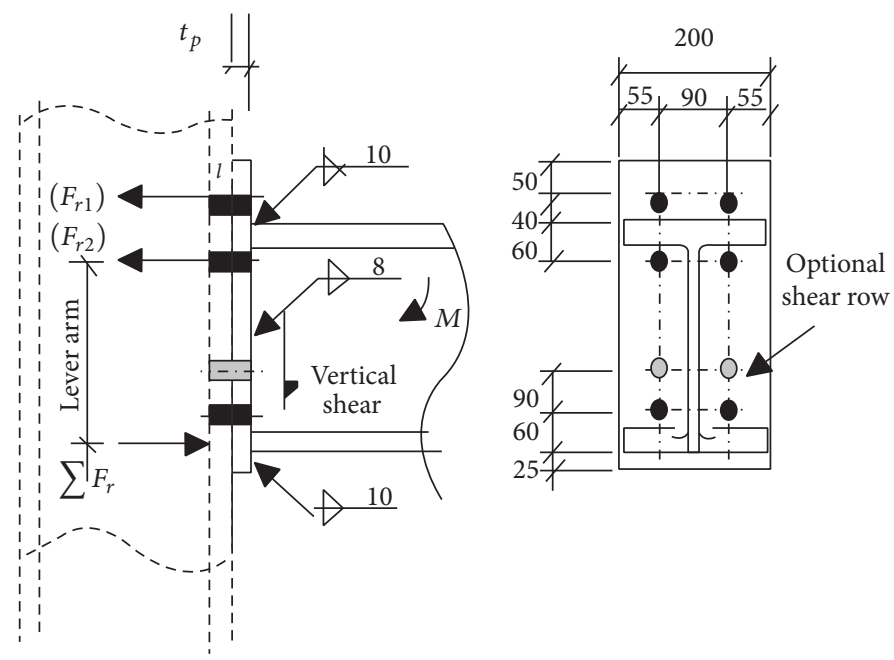

FIGURE 5: Unstiffened extended end-plate connection as partial strength connections.

3.2. Design Example. To show the adequacy of suggested method, the moment steel portal frame having semirigid connections was considered as shown in Figure 4 already studied by Kameshki and Saka [21].

The proposed connections are designed using unstiffened extended end-plate as shown in Figure 5. The required curve fitting and constant parameters for moment-rotation curve are given in (5) and considered as follows [18] (all size parameters are in inches):

$$
\begin{aligned}
& c_{1}=1.83 \times 10^{-3} \\
& c_{2}=-1.04 \times 10^{-4} \\
& c_{3}=6.38 \times 10^{-6} \\
& k=d_{g}{ }^{-2.4} t_{p}{ }^{-0.4} d_{b}{ }^{-1.5},
\end{aligned}
$$

where $d_{g}$ is lever arm, $t_{p}$ is thickness of end-plate, and $d_{b}$ is the diameter of the bolts. In this example the thickness of end-plate is considered as $12 \mathrm{~mm}$. The value of lever arm has a relationship with the connected beam depth. The bolt diameter was designed in accordance with British standard BS5950 for bending moment and shear consideration. By using this information (5) can determine the stiffness of semirigid connection for different value of moment. American wide flange sections with grade steel of A36 were used for both beams and columns. The modulus of elasticity is $210 \times 10^{6} \mathrm{kN} / \mathrm{m}^{2}$.

To show the effects of semirigid connections on structural performance, the analyses of portal frame with rigid connections were also considered. Both steel frames design was performed in accordance with the 2010 AISC direct analysis method (AISC 360-10/IBC 2006). The results of both frames are summarized and given in Table 1. It is apparent from 
TABLE 1: Structural performance of frame with semirigid and rigid connections [21].

\begin{tabular}{lccc}
\hline $\begin{array}{l}\text { Component } \\
\text { number }\end{array}$ & Component type & Rigid-frame & Semirigid frame \\
\hline 1 & Column & $\mathrm{W} 24 \times 68$ & $\mathrm{~W} 21 \times 73$ \\
2 & Column & $\mathrm{W} 21 \times 73$ & $\mathrm{~W} 21 \times 73$ \\
3 & Column & $\mathrm{W} 18 \times 40$ & $\mathrm{~W} 6 \times 15$ \\
4 & Column & $\mathrm{W} 21 \times 50$ & $\mathrm{~W} 24 \times 68$ \\
5 & Column & $\mathrm{W} 16 \times 36$ & $\mathrm{~W} 18 \times 35$ \\
6 & Column & $\mathrm{W} 12 \times 40$ & $\mathrm{~W} 18 \times 35$ \\
7 & Beam & $\mathrm{W} 18 \times 35$ & $\mathrm{~W} 16 \times 26$ \\
\hline $\begin{array}{l}\text { Total weight } \\
\text { (kg) }\end{array}$ & & 4574.00 & 3938.10 \\
$\begin{array}{l}\text { Top storey } \\
\text { displacement } \\
(\mathrm{cm})\end{array}$ & & & \\
$\begin{array}{l}\text { Maximum } \\
\text { interstorey drift }\end{array}$ & & 0.96 & 1.20 \\
\hline
\end{tabular}

TABLE 2: Sectional properties of 5-, 10-, and 15-storey frames.

\begin{tabular}{|c|c|c|c|}
\hline Storey & 5-storey frame & 10 -storey frame & 15 -storey frame \\
\hline \multicolumn{4}{|c|}{ Column section } \\
\hline $1-3$ & $\mathrm{~W} 12 \times 87$ & $\mathrm{~W} 27 \times 102$ & $\mathrm{~W} 33 \times 152$ \\
\hline $4-6$ & $\mathrm{~W} 12 \times 19$ & $\mathrm{~W} 24 \times 68$ & $\mathrm{~W} 30 \times 148$ \\
\hline $7-9$ & - & $\mathrm{W} 24 \times 55$ & $\mathrm{~W} 24 \times 84$ \\
\hline $10-12$ & - & $\mathrm{W} 14 \times 22$ & $\mathrm{~W} 21 \times 73$ \\
\hline $13-15$ & - & & $\mathrm{W} 16 \times 57$ \\
\hline \multicolumn{4}{|c|}{ Beam section } \\
\hline $1-3$ & $\mathrm{~W} 14 \times 38$ & $\mathrm{~W} 14 \times 48$ & $\mathrm{~W} 14 \times 53$ \\
\hline $4-6$ & $\mathrm{~W} 14 \times 34$ & $\mathrm{~W} 14 \times 48$ & $\mathrm{~W} 14 \times 53$ \\
\hline $7-9$ & - & $\mathrm{W} 14 \times 48$ & $\mathrm{~W} 14 \times 48$ \\
\hline $10-12$ & - & $\mathrm{W} 12 \times 40$ & $\mathrm{~W} 12 \times 40$ \\
\hline $13-15$ & - & & $\mathrm{W} 10 \times 39$ \\
\hline
\end{tabular}

Table 1 that frame having semirigid connections is around 11 percent lighter compared to the rigid one. However, it experienced 25 percent more lateral displacement.

\section{Performance of Portal Frames with Semirigid Connections Using Nonlinear Time History Analysis}

4.1. Description of Specimens. To evaluate the connection semirigidity effects on steel portal frames subjected to the ground acceleration 5-, 10-, and 15-storey frames were considered as shown in Figure 6. The frames were considered as residential buildings and designed according to AISC direct analysis method (AISC 360-10/IBC 2006). The $5 \mathrm{KN} / \mathrm{m}$ and $2 \mathrm{KN} / \mathrm{m}$ were assigned to the beams representative of dead and live load, respectively. The $\mathrm{W}$ sections were used for beam and column in all three frames as shown in Table 2.
For each analysis, kinematic hysteresis models along with individual stiffness were assigned to the connections. The stiffness was calculated from 6 full-scale experimental tests of flush end-plate connection with variable parameters including number of bolt rows, thickness of end-plate, and bolts size. A test rig was considered to accommodate a $3 \mathrm{~m}$ height column and a $1.3 \mathrm{~m}$ span of cantilever beam as shown in Figure 7. A hydraulic jack is applied the concentrated load at the tip of connected beam. The loading of the specimen was performed using $5 \mathrm{kN}$ increments until the occurrence of a substantial deflection in the beam. A series of tensile tests were conducted on the web and flange of column, beam, and end-plate of the specimen. The average value of yield and ultimate strength were $338 \mathrm{~N} / \mathrm{mm}^{2}$ and $502 \mathrm{~N} / \mathrm{mm}^{2}$, respectively.

The moment-rotation curves for all the six beam-tocolumn connections are shown in Figure 8. In all the tests, the specimens experienced linear behaviour in the first stage and then are followed by nonlinear behaviour, slowly dropping the stiffness by increasing the rotation. It is mainly due to the concentrated deformation appearing at the tension region of the connections through the top bolt rows as shown in Figure 9.

The results of the initial stiffness, moment capacity, and maximum rotation for all the six beam-to-column connections are given in Table 3 . The rotation stiffness of the connection depends on the geometrical configuration of the connection. Generally, the higher the moment resistance of the connection, the stiffer the connection's stiffness. However, factor such as number of bolts, thickness of the plate, and depth of the beam play an important role to determine the stiffness of the connection. Therefore, it is the best way to represent the rotation stiffness of the connection by comparing the moment resistance and relate to other connection's parameters.

4.2. Hysteresis Models. Hysteresis is the process of energy dissipation through deformation (displacement) that affects nonlinear static and nonlinear time history load cases. Several different hysteresis models are available to describe the behaviour of different types of materials. For the most part, these differ in the amount of energy they dissipate in a given cycle of deformation and how the energy dissipation behaviour changes with an increasing amount of deformation. Typical for all models, cyclic loading behaves as follows:

(i) Initial loading in the positive or negative direction follows the backbone curve.

(ii) During the reversal deformation, unloading occurs along a different path, usually steeper than the loading path.

(iii) After the load level is reduced to zero, continued reversal of deformation causes reverse loading along a path that eventually joins the back bone curve on the opposite side.

Figure 9 shows kinematic hysteresis model. It is based upon the kinematic hardening behaviour that is commonly observed in metals, and it is the default hysteresis model for 

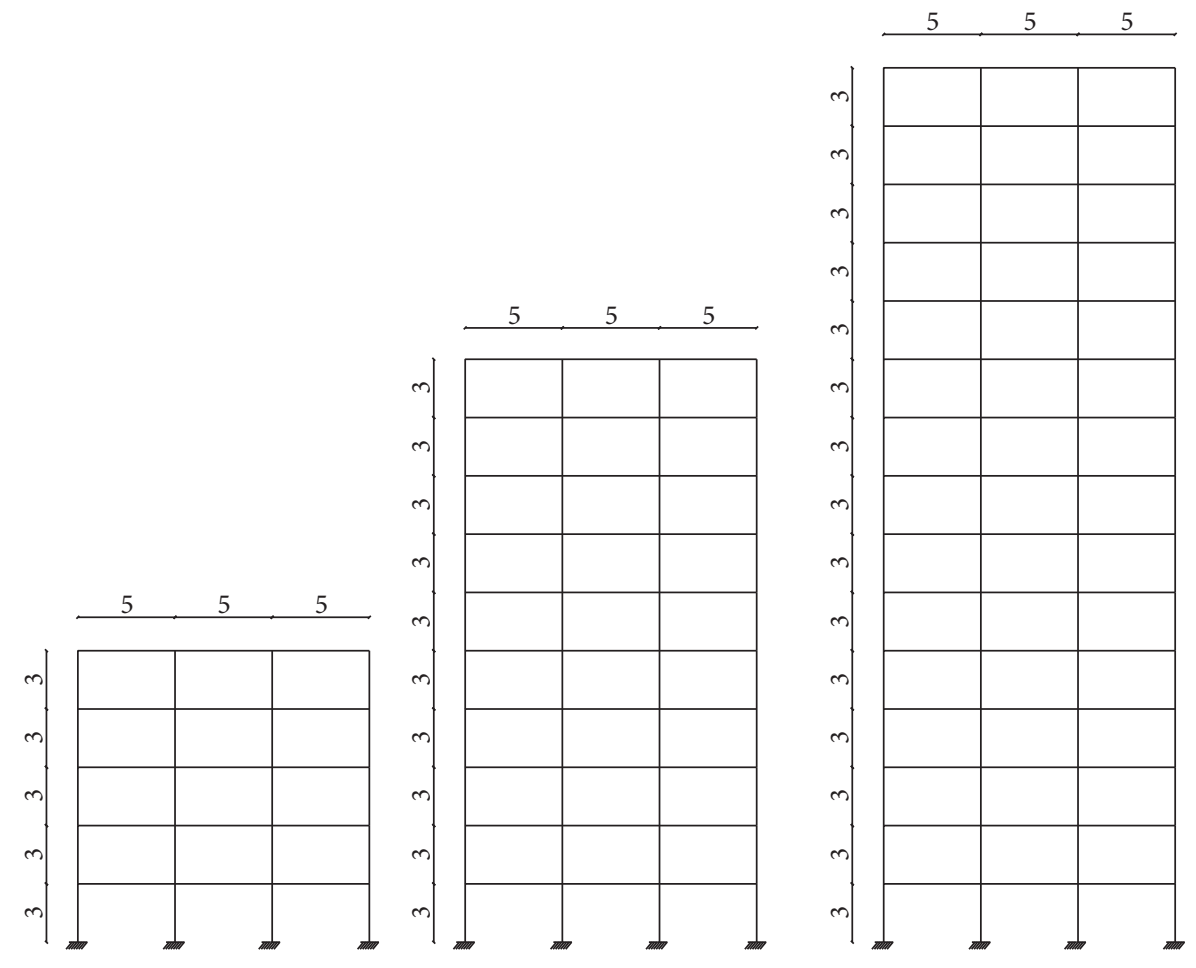

FIGURE 6: 5-, 10-, and 15-storey portal frames.

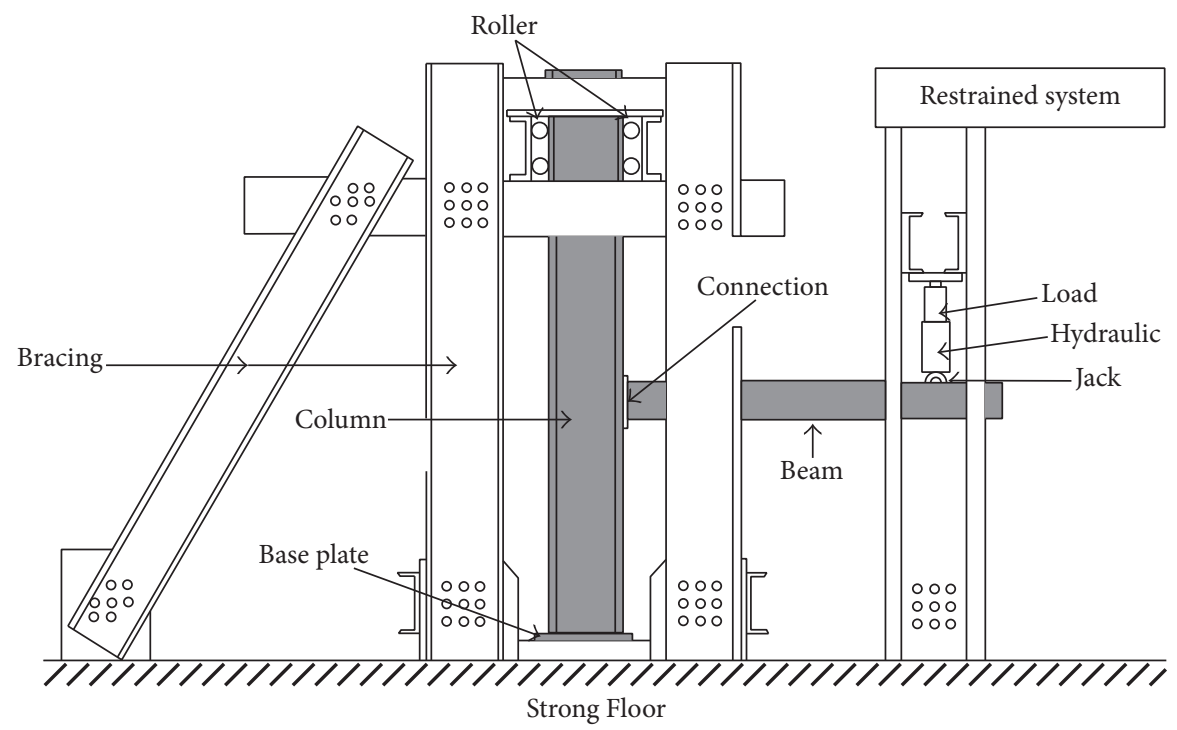

FIGURE 7: Test rig for full-scale testing.

all metal materials. This model dissipates a significant amount of energy and is appropriate for ductile materials. Under the rules of kinematic hardening, the plastic deformation occurs in one direction and "pulls" the curve in the other direction.

4.3. Earthquake Ground Motions. To perform nonlinear dynamic analysis, it is crucial to select earthquake records proportional to the geotechnical properties and soil conditions of the site. In this research the intended frames have been designed on rock beds of soil site class B in compliance with response spectrum of IBC 2009 code. Accordingly, 10 ground motion records were considered from Pacific Earthquake Engineering Research Center (PEER) as given in Table 4.

4.4. Results and Discussion. Figures 11 to 13 show the base shear versus displacement for 5-, 10-, and 15-storey frames, respectively. The analyses were accomplished through 


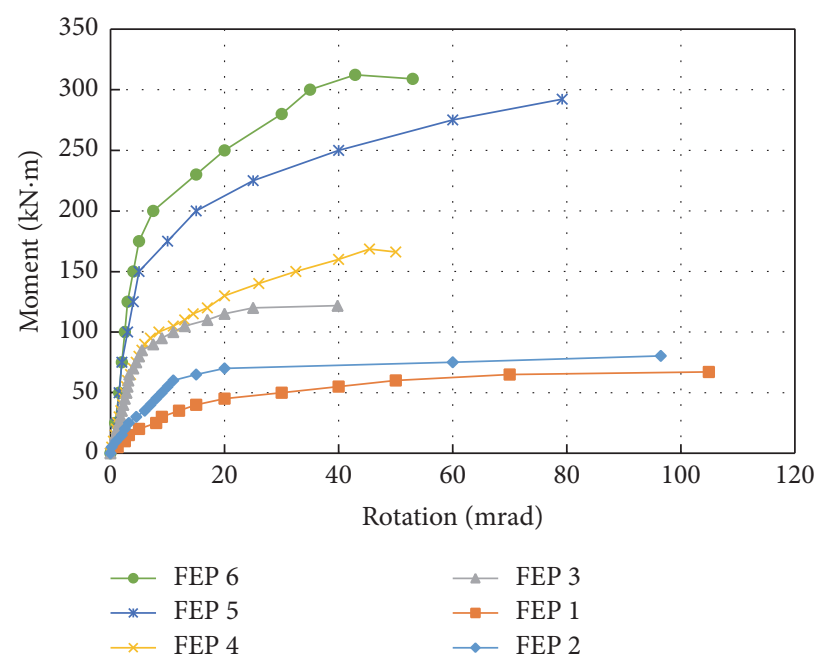

Figure 8: Moment-rotation curves of flush end-plate connections.
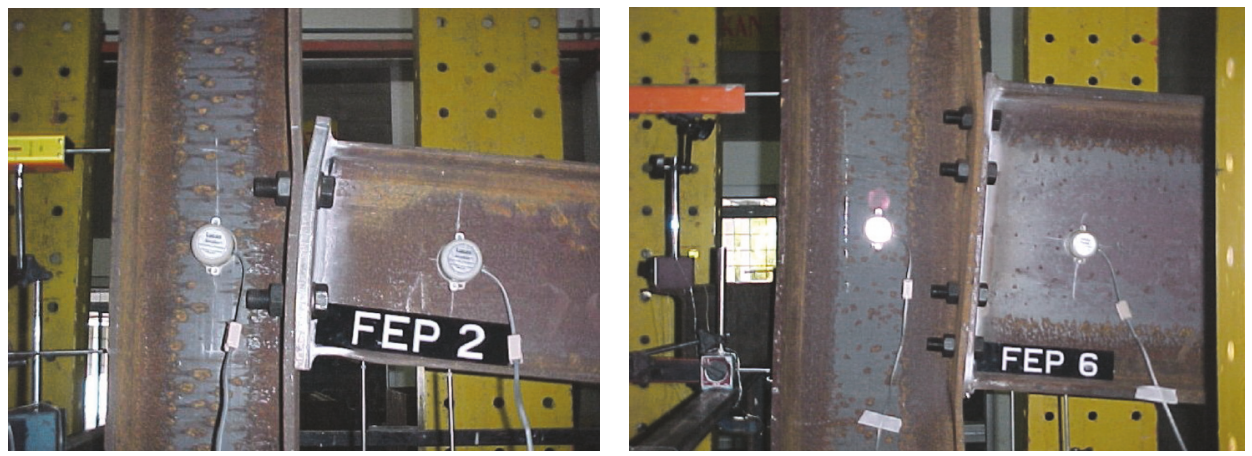

Figure 9: Failure mode at the end of the test.

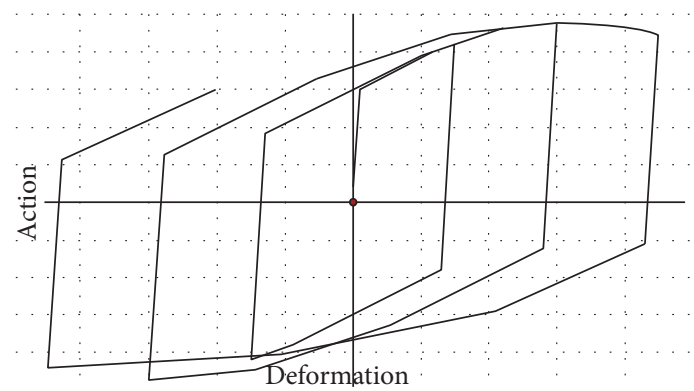

FIgURE 10: Kinematic hysteresis model.

displacement controlled and incremental lateral loads were applied on frames having fully rigid beam-to-column connections. The pushover analyses were carried out and monotonically increased till the 1.5 times target displacement was reached. The triangular pattern of loading was applied to the frames and plastic hinge rotation angle was the main parameter to identify the performance level (immediate occupancy, life safety, and collapse prevention). The equivalent base shear and maximum displacement at the top for boundary states (immediate occupancy, life safety, and collapse prevention) are demonstrated on the capacity curves for all frames where it shows the life safety requirement satisfied.

To study the seismic performance of the semirigid and fully rigid frames, the time history analyses were compared with pushover analysis. As can be seen in the Figures 11 to 13 , the maximum base shear in the time history analyses was greater than the amount determined from the pushover analyses. Generally, when the connection stiffness decreased, the maximum base shear also decreased. The displacement at the top in 5- and 15-storey frames experienced increase up to $30 \%$ by decreasing the connection stiffness from rigid to semirigid $(\mathrm{K} 3100 \mathrm{kNm} / \mathrm{R})$. However, this issue was not accurate for 10-storey frame. By comparing Figures 10 to 12 there is no direct relationship between connection stiffness and maximum displacement at the top in tall buildings, as it is mainly controlled by ground motion and frame characteristic such as first mode period.

\section{Conclusions}

This study evaluates seismic performance of steel portal frames with semirigid connections. The nonlinear stiffness matrix method was developed to investigate the effects of 
TABLE 3: Results of all the six beam-to-column connections.

\begin{tabular}{|c|c|c|c|c|c|c|c|c|}
\hline Specimen & $\begin{array}{l}\text { Moment of } \\
\text { inertia of } \\
\text { beam }\left(\mathrm{cm}^{4}\right)\end{array}$ & $\begin{array}{l}\text { Number of } \\
\text { bolts in row }\end{array}$ & $\begin{array}{c}\text { Diameter of } \\
\text { slot } \\
(\mathrm{mm})\end{array}$ & $\begin{array}{l}\text { End-plate } \\
\text { thickness } \\
(\mathrm{mm})\end{array}$ & $\begin{array}{c}\text { Moment } \\
\text { resistance, } \\
M_{i} \\
(\mathrm{kNm})\end{array}$ & $\begin{array}{l}\text { Rotation, } \theta_{i} \\
\quad(\mathrm{mRad})\end{array}$ & $\begin{array}{l}\text { Initial stiffness, } \\
S_{j, \text { ini }}=M_{i} / \theta_{i} \\
(\mathrm{kNm} / \mathrm{mRad})\end{array}$ & $\begin{array}{l}\text { Max rotation at } \\
\text { max load, } \theta_{u} \\
(\mathrm{mRad})\end{array}$ \\
\hline FEP 1 & 3450 & 1 & 20 & $\begin{array}{c}12 \\
(\mathrm{~W}=200)\end{array}$ & 35.1 & 11.3 & 3.1 & 104.9 \\
\hline FEP 2 & 3450 & 1 & 24 & $\begin{array}{c}15 \\
(\mathrm{~W}=200)\end{array}$ & 70.3 & 12.4 & 5.6 & 96.5 \\
\hline FEP 3 & 23457 & 2 & 20 & $\begin{array}{c}12 \\
(\mathrm{~W}=200)\end{array}$ & 81.5 & 6.8 & 12.0 & 39.8 \\
\hline FEP 4 & 23457 & 2 & 20 & $\begin{array}{c}12 \\
(\mathrm{~W}=250)\end{array}$ & 95.0 & 6.0 & 15.8 & 45.4 \\
\hline FEP 5 & 55481 & 2 & 24 & $\begin{array}{c}15 \\
(\mathrm{~W}=200)\end{array}$ & 200.0 & 6.0 & 33.0 & 79.2 \\
\hline FEP 6 & 55481 & 2 & 24 & $\begin{array}{c}15 \\
(\mathrm{~W}=250)\end{array}$ & 192.0 & 5.2 & 36.9 & 42.9 \\
\hline
\end{tabular}

TABLE 4: Different places of ground motions as per PEER records.

\begin{tabular}{lccccc}
\hline Earthquake & Station & PGA $(\mathrm{g})$ & Earthquake & Station & PGA (g) \\
\hline Northridge & 24087 Arleta-Nordhoff & 0.344 & Loma Prieta & 47381 Gilroy Array \#3 & 0.555 \\
Northridge & 24278 Castaic-Old Ridge & 0.217 & Victoria, Mexico & 6604 Cerro Prieto & 0.621 \\
Northridge & 24303 LA-Hollywood & 0.358 & Westmorland & 5051 Parachute Test Site \\
Northridge & 24514 Sylmar-Olive View & 0.535 & Kern County & 1095 Taft Lincoln School & 0.242 \\
Loma Prieta & 1028 Hollister City Hall & 0.247 & CapeMendocino & 89324 Rio Dell Overpass -FF & 0.385 \\
\hline
\end{tabular}

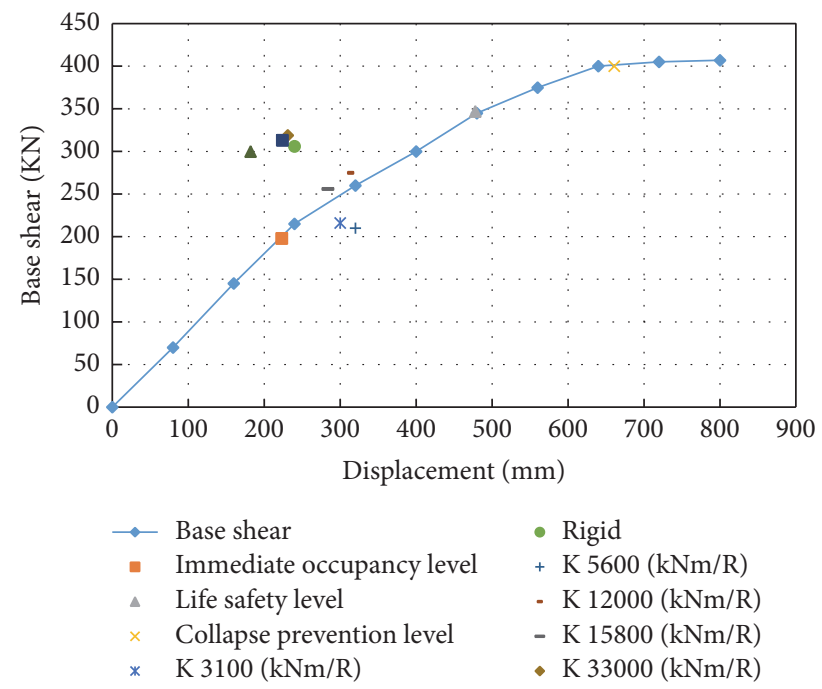

FIGURE 11: Base shear versus displacement at the top (5-storey frame).

beam-to-column connection rigidity and geometric nonlinearity in the seismic response. Besides, three portal frames

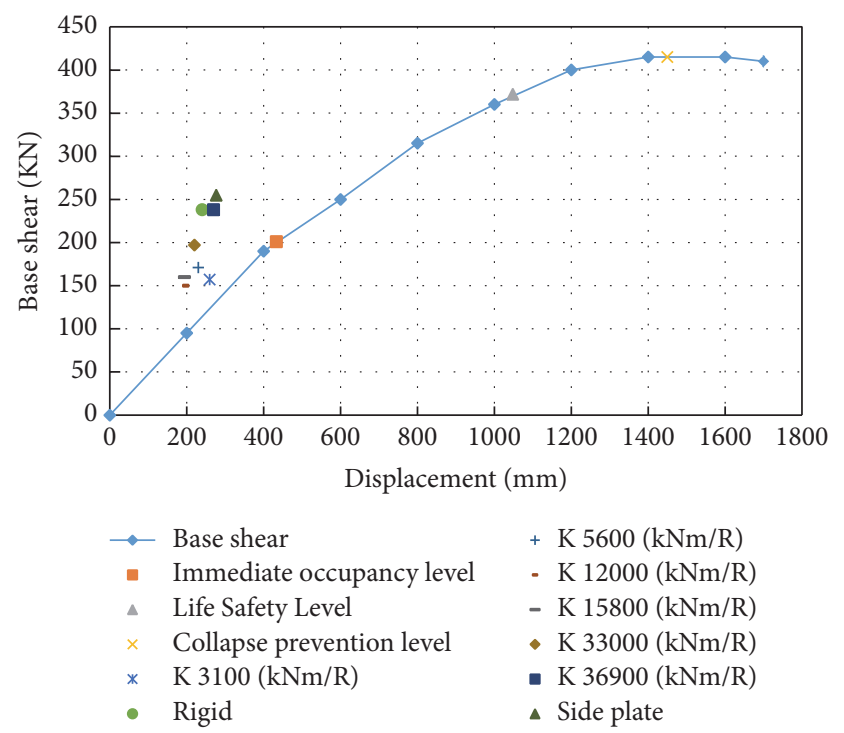

FIGURE 12: Base shear versus displacement at the top (10-storey frame).

with different connection stiffness were taken into consideration and their seismic performance was evaluated through 


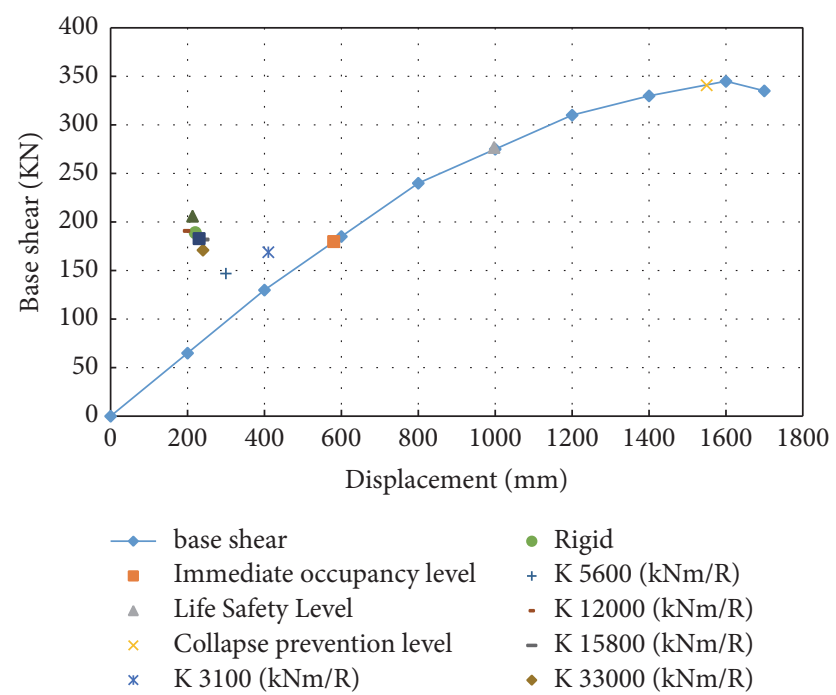

FIGURE 13: Base shear versus displacement at the top (15-storey frame).

time history analysis. The following points emerged from the present investigation:

(i) It was noticed that the semirigid connection modelling produced lighter frames compared to the rigid one.

(ii) Beam-to-column connection flexibility affects the force distribution in the frame and causes decrease in the base shear.

(iii) It was concluded that there is no linear relationship between connection stiffness and maximum displacement at the top. The maximum displacement at the top in high-rise frame is mainly controlled by frame properties and ground motion level.

(iv) Current design code does not take into account adequate design method for frames with semirigid connections for high seismic areas. Specially, for research concern the seismic force distribution and the analysis subjected to the gravity loads need further investigation. Considerably more work will need to be done to determine the cyclic performance of partial strength/semirigid connections.

\section{Conflicts of Interest}

The authors declare that they have no conflicts of interest.

\section{Acknowledgments}

The authors wish to thank the esteemed technical staff of the Structures and Materials Laboratory, Universiti Teknologi Malaysia (UTM), for their cooperation on and support of this study. Financial support provided by the Universiti Teknologi Malaysia Construction Research Centre (CRC) for conducting the experimental work was invaluable and authors remain obliged.

\section{References}

[1] N. Kishi and W.-F. Chen, "Moment-rotation relations of semirigid connections with angles," Journal of Structural Engineering, vol. 116, no. 7, pp. 1813-1834, 1990.

[2] Y. L. Yee and R. E. Melchers, "Moment-rotation curves for bolted connections," Journal of Structural Engineering, vol. 112, no. 3, pp. 615-635, 1986.

[3] A. R. Kukreti, T. M. Murray, and A. Abolmaali, "End-plate connection moment-rotation relationship," Journal of Constructional Steel Research, vol. 8, pp. 137-157, 1987.

[4] E. Attiogbe and G. Morris, "Moment-rotation functions for steel connections," Journal of Structural Engineering, vol. 117, no. 6, pp. 1703-1718, 1991.

[5] Y. J. Shi, S. L. Chan, and Y. L. Wong, "Modeling for momentrotation characteristics for end-plate connections," Journal of Structural Engineering, vol. 122, no. 11, pp. 1300-1306, 1996.

[6] S.-S. Lee and T.-S. Moon, "Moment-rotation model of semirigid connections with angles," Engineering Structures, vol. 24, no. 2, pp. 227-237, 2002.

[7] A. S. Elnashai, A. Y. Elghazouli, and F. A. Denesh-Ashtiani, "Response of semirigid steel frames to cyclic and earthquake loads," Journal of Structural Engineering, vol. 124, no. 8, pp. 857867,1998

[8] S. L. Chan and P. T. Chui, Non-Linear Static and Cyclic Analysis of Steel Frames with Semi-Rigid Connections, Elsevier, Amsterdam, Netherlands, 2000.

[9] J. C. Awkar and E. M. Lui, "Seismic analysis and response of multistory semirigid frames," Engineering Structures, vol. 21, no. 5, pp. 425-441, 1999.

[10] M. Saravanan, S. Arul Jayachandran, V. Marimuthu, and P. Prabha, "Advanced analysis of cyclic behaviour of plane steel frames with semi-rigid connections," Steel and Composite Structures, vol. 9, no. 4, pp. 381-395, 2009.

[11] G. Shi, Y. Shi, Y. Wang, S. Li, and H. Chen, "Experimental study of semirigid end-plate connections in multi-story steel frames," Journal of Tsinghua University, vol. 44, no. 3, pp. 391-394, 2004.

[12] M. N. Nader and A. Astaneh, "Dynamic behavior of flexible, semirigid and rigid steel frames," Journal of Constructional Steel Research, vol. 18, no. 3, pp. 179-192, 1991.

[13] W. F. Chen, Y. Goto, and J. R. Liew, Stability Design of Semi-Rigid Frames, vol. 1, John Wiley \& Sons, 1996.

[14] B. Guo and A. Chen, "Finite element analysis and behavior of semi-rigid steel frames," Journal of Building Structures, vol. 22, no. 5, pp. 48-52, 2001.

[15] H. R. Valipour and M. A. Bradford, "Nonlinear P- $\Delta$ analysis of steel frames with semi-rigid connections," Steel and Composite Structures, vol. 14, no. 1, pp. 1-20, 2013.

[16] A.I.O.S. Construction, Ed., Specification for Structural Steel Buildings (ANSI/AISC 360-10), AISC Committee on Specifications, 2010.

[17] T. E. Standard, Ed., Eurocode 3: Design of Steel Structures (Part 1-8: Design of Joints), 2005.

[18] W. F. Chen and E. M. Lui, Stability Design of Steel Frames, CRC Press, 1991.

[19] P. Grundy, "Stability and design of frames with flexible connections," Transactions of the Institution of Engineers, Australia. Civil Engineering, vol. 28, no. 2, pp. 190-194, 1986.

[20] K. Majid, Matrix Methods of Analysis and Design by Computers: Nonlinear Structures, Butterworths, London, UK, 1972.

[21] E. S. Kameshki and M. P. Saka, "Optimum design of nonlinear steel frames with semi-rigid connections using a genetic algorithm," Computers \& Structures, vol. 79, no. 17, pp. 1593-1604, 2001. 


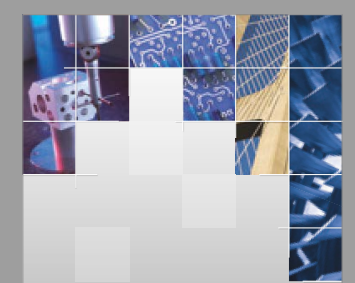

\section{Enfincering}
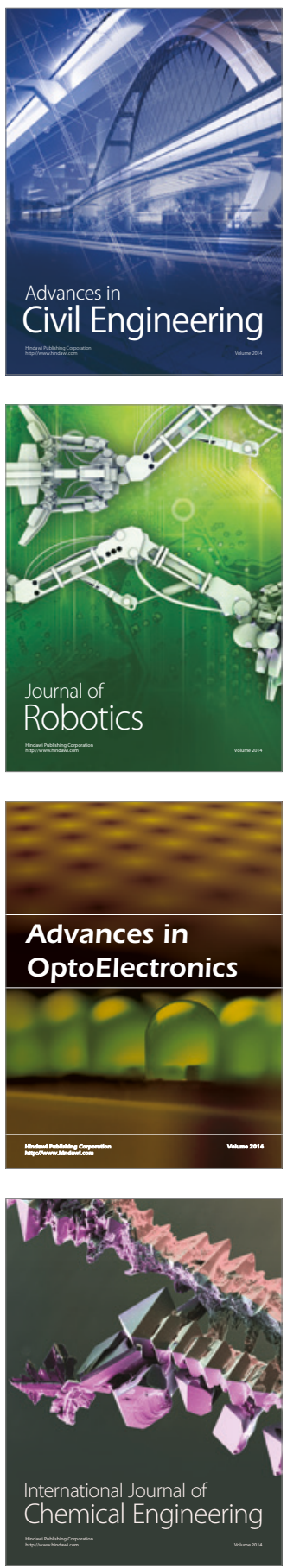

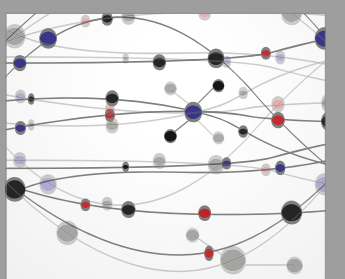

The Scientific World Journal

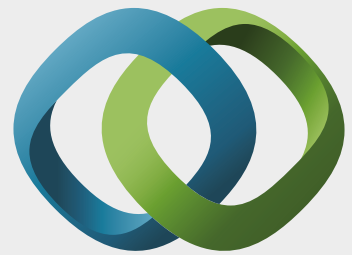

\section{Hindawi}

Submit your manuscripts at

https://www.hindawi.com
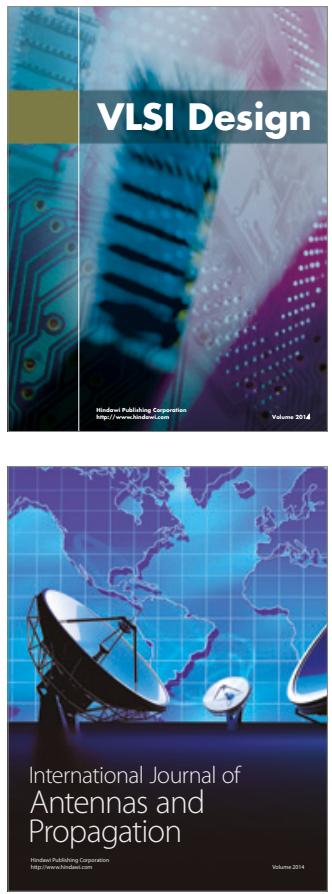

\section{Rotating}

Machinery
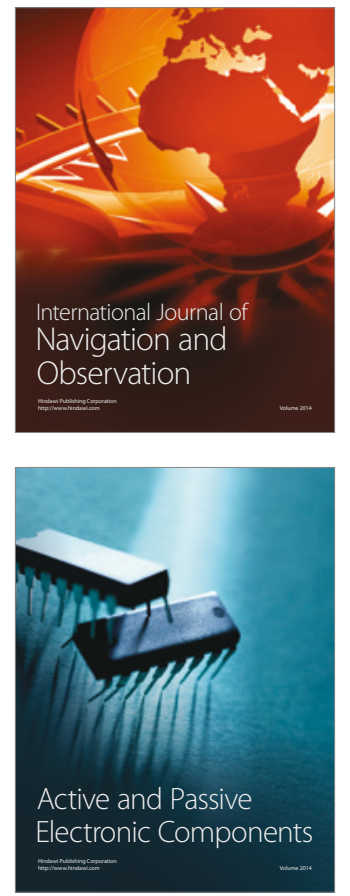
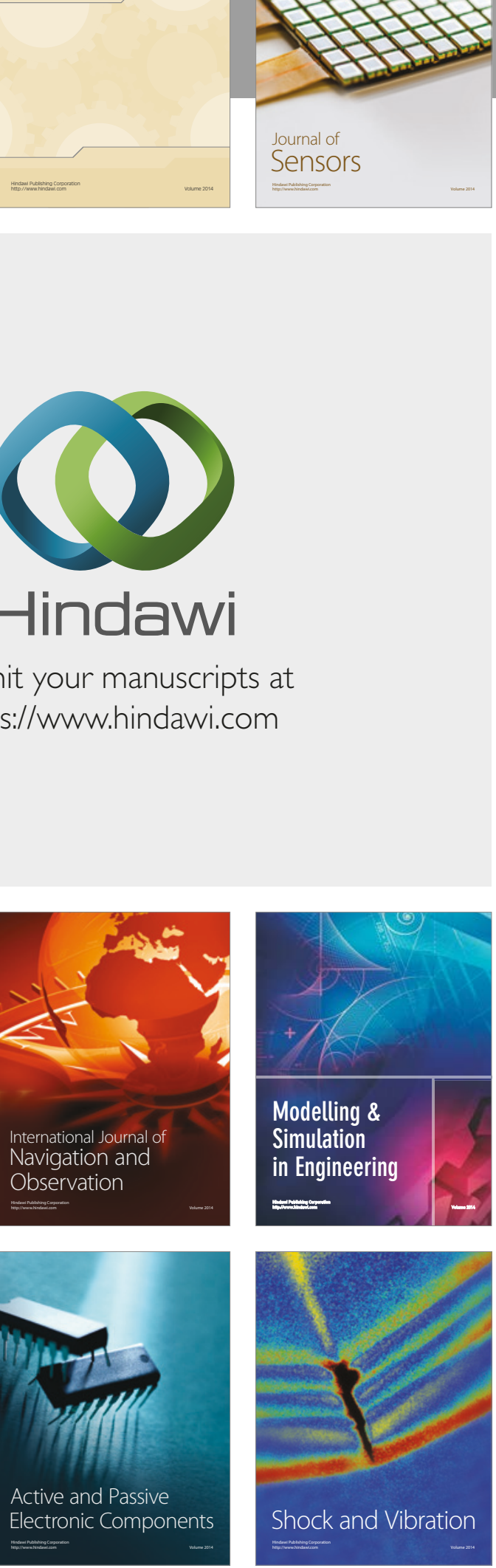
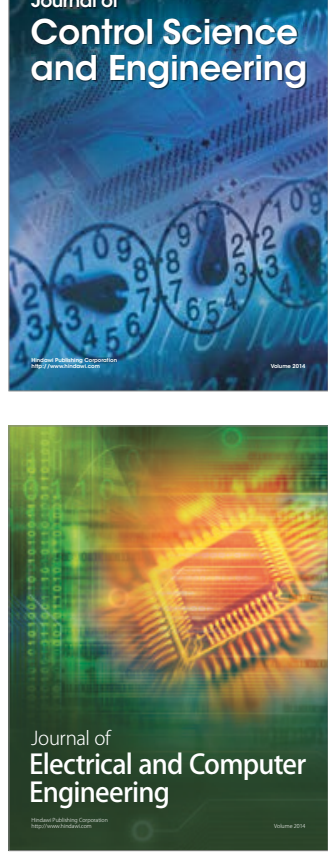

Distributed

Journal of

Control Science

and Engineering
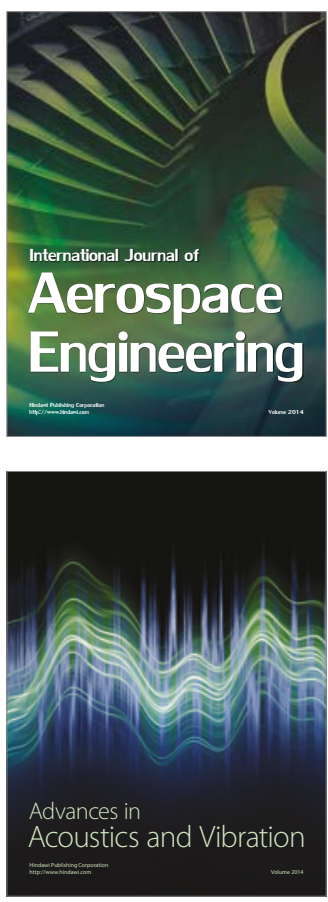

Sensor Networks 